American Journal of Pharmaceutical Education 2018; 82 (4) Article 7086.

\title{
COMMENTARY
}

\section{Self-Help for the Pharmacy Educator}

\author{
Tyler Rose, $\mathrm{PhD}^{\mathrm{a}, \mathrm{b}}$ \\ ${ }^{a}$ Roseman University of Health Sciences College of Pharmacy, South Jordan, Utah \\ ${ }^{\mathrm{b}}$ Editorial Board Member, American Journal of Pharmaceutical Education, Arlington, Virginia \\ Submitted March 30, 2018; accepted April 6, 2018; published May 2018.
}

Good news! Research supports the idea that effective teaching improves learning in post-secondary students. One study analyzed the effectiveness of more than 2,000 instructors of college algebra over a 10 -year period by measuring how well students who passed their classes performed in subsequent courses in the math sequence. The main finding was that a one standard deviation (SD) increase in instructor effectiveness corresponded to a 0.2 SD increase in grades and a 0.4 SD increase in final exam scores in the follow-on course. The authors put this result in perspective by noting a similar performance difference exists between students with a 3.0 and 2.0 incoming GPA. ${ }^{1}$ To some pharmacy educators, results like these only validate the obvious. Others, who may be questioning the impact of their teaching in an era where students seem to have a vast choice of alternative learning streams, might find these results encouraging.

Now for the bad news: researchers are still unclear on exactly what qualities make a teacher "effective." Some criteria have been suggested, but identifying all the key elements and measuring them with confidence is a challenging proposition. ${ }^{2-4}$ So waiting for science to unambiguously identify an all-purpose recipe for teaching effectiveness may take more time than the average pharmacy educator has left in their teaching career. Nevertheless, one essential aspect of being an effective teacher almost certainly has to be the degree to which one uses effective teaching methods. And educators familiarize themselves with effective teaching methods by engaging in professional development. Indeed, a study with middle and high school teachers found teacher efficacy correlated positively with teacher professional development, but not with the teachers' own undergraduate qualifications or scholastic aptitude. ${ }^{5}$

To meet accreditation standards, pharmacy colleges are required to provide opportunities for professional development to their faculty, ${ }^{6}$ but college-wide faculty

Corresponding Author: Tyler Rose, Roseman University of Health Sciences College of Pharmacy, 10920 S. River Front Pkwy., South Jordan, UT 84095. Tel: 801-878-1075. E-mail: trose@roseman.edu development programs can suffer from a number of drawbacks, such as a lack of the consistency and follow-up necessary to effect meaningful change, a lack of programming to address the specific needs of subsets of faculty, and a lack of program accessibility for all faculty members. Many innovative suggestions have been put forward in the literature to address these and other deficiencies in program-wide faculty development. ${ }^{7-11}$ And, no doubt, colleges that invest the resources to make their faculty development programs more practical, targeted, and relevant are going to reap more benefits than those that don't. Yet there is a liberating truth that circumvents all the limitations of a college-driven faculty development program: a faculty member's development is ultimately their own, personal responsibility.

Each of us can ensure our development as teachers (or in any other role) is targeted, relevant, accessible, and consistent, if we make development a regular, personal habit. Following are three things to consider for faculty members who want to become more autonomous in their growth as pharmacy educators.

\section{Motivation and Self-Reflection}

Motivation helps promote and sustain self-regulated learning. ${ }^{12}$ Previous work has found that one of the greatest motivators for professional development in teachers is a desire to address student learning needs. ${ }^{13}$ This suggests that teachers who are motivated to engage in professional development have, to one degree or another, a sense of dissatisfaction with their teaching effectiveness; or, looked at another way, they maintain high teaching ideals they feel they have not yet attained in one or more respects. Thus, acquiring an elevated vision for teaching can provide a strong impetus for self-improvement.

An elevated vision for teaching can be constructed from a number of different experiences. Examples include attending a talk or roundtable at an organization meeting; reading a review, research article, or opinion piece in a journal or a blog; engaging in constructive discussion with colleagues about student learning needs and how to address these needs; assisting struggling students; being evaluated in the classroom by a colleague or 


\section{American Journal of Pharmaceutical Education 2018; 82 (4) Article 7086.}

students; evaluating the teaching of a colleague; or, of course, consuming content from a programmed faculty development event. Some time for reflection is required to stitch these varied experiences into a cohesive vision for effective teaching. Reflection of the brutally honest variety is then required to identify ways in which one's current teaching practice falls short of this vision.

An infamous study conducted several decades ago at an American university (not the University of Lake Woebegone) once reported that over $90 \%$ of surveyed professors rated themselves as better-than-average teachers, with two-thirds placing themselves in the top quartile. ${ }^{14}$ While allowing that a healthy sense of self-confidence can enhance performance, it is possible that too much can promote complacency, the antithesis of motivation. So, how do you rate yourself as a teacher? What evidence, if any, would you use for your self-assessment? Rigorous honesty in identifying areas for improvement can help establish the sense of dissatisfaction necessary to motivate self-driven professional development.

\section{Knowledge Acquisition and Implementation}

Learning about teaching and learning is important, but implementation of this knowledge is key to improving teaching efficacy. A quote from a text on teaching theory published in the early $20^{\text {th }}$ century provides this insight: "Unused knowledge is knowledge dead or dying. All knowledge which any of us can really claim to possess is that which has been turned over and over in use, use so frequent as to prevent decay." 15 Often, the same sources that provide a vision of effective teaching will also provide information about one or more supporting methodologies that can be implemented in practice. Background research may be necessary to establish whether there is evidence a new technique will yield desirable results, suggest ways in which a general method can be adapted to a specific teaching situation, and give a sense for the amount of time required for implementation. It is important to consider whether potential learning benefits will outweigh the time costs for implementation. ${ }^{16}$ Encouragingly, a study following 28 pharmacy faculty members who implemented a variety of new methods into their teaching found the majority reported only about 9 hours were required for implementation of the new methods, including background research. ${ }^{17}$ The remaining faculty members incorporated their new methods over the course of a year, suggesting that sometimes significantly more time may be required for implementation, especially if incorporation of a new methodology necessitates upstream changes in the class learning objectives or downstream changes in assessment.

\section{Assessment}

Assessing the effects of a teaching intervention is important because it provides evidence for whether the new method was beneficial. Lack of such evidence may mean the technique should be modified or abandoned altogether. When modifications are required, good assessment data may point to what kind of modifications should be made. In the study of the pharmacy faculty members who implemented new methods in their classes, more than half indicated a desire to make modifications to their new technique the following year. ${ }^{17}$

Coming up with an assessment method at an early stage, perhaps the same time the intervention is planned, helps define the purpose of the intervention. For example, is it expected to improve student engagement, consolidation of knowledge, or application of skills? The inability to identify a clearly assessable endpoint suggests an intervention may not provide any real learning benefit, which will allow you to modify or abandon it before too much time is expended on its implementation.

When we speak of teacher development in higher education, it is often synonymous with the concept of scholarly teaching - a largely self-driven process that involves selecting and applying appropriate information from the teaching/learning literature, collecting systematic observations and evaluations, and analyzing the outcomes. ${ }^{18}$ However, scholarly teaching does not always rise to the level of the scholarship of teaching and learning (SOTL), which seeks to make generalizable contributions to the understanding of how effective teaching and learning occur and often involves novel interventions. ${ }^{19}$ As such, the methods for assessing scholarly teaching do not need to be as rigorous as those required for a research publication. Perhaps informal observations will be sufficient. However, assessment should be rigorous enough to convince you and other interested parties (eg, students, administrators, promotion bodies) that your choice of classroom activities is sound, or at least moving purposefully in the right direction. In general, the more extraordinary the teaching method, the more extraordinary the proof ought to be of its value.

The three points elaborated here dovetail to form an iterative cycle. Ideally, assessment will help provide the motivation to once again self-reflect, return to the literature, try something new, and evaluate the results. As a case in point, $96 \%$ of the faculty who implemented new teaching techniques in the previously cited study felt it was worth the effort and expressed a desire to do it again. ${ }^{17}$ These were people who had experienced the rewards of self-development. Likewise, improved efficacy, educational impact, and intellectual revitalization await our decision to invest in our own development as teachers. 


\section{American Journal of Pharmaceutical Education 2018; 82 (4) Article 7086.}

\section{REFERENCES}

1. De Vlieger P, Jacob B, Stange K. Measuring instructor effectiveness in higher education. In: Productivity in Higher Education. Hoxby CM, Stange K, eds. Chicago, IL: University of Chicago Press; 2017.

2. Dee TS. Teachers, race, and student achievement in a randomized experiment. Rev Econ Stat. 2004;86(1):195-210.

3. Goldhaber D, Anthony E. Can teacher quality be effectively assessed? National board certification as a signal of effective teaching. Rev Econ Stat. 2007;89(1):134-150.

4. Hoffmann F, Oreopoulos P. A professor like me the influence of instructor gender on college achievement. J Human Res. 2009;44(2): 479-494.

5. Harris DN, Sass TR. Teacher training, teacher quality and student achievement. J Public Econ. 2011;95(7-8):798-812.

6. Accreditation Council for Pharmacy Education. Accreditation standards and key elements for the professional program in pharmacy leading to the doctor of pharmacy degree. Standards 2016. https:// www.acpe-accredit.org/pdf/Standards2016FINAL.pdf. Accessed March 16, 2018.

7. Brock TP, Assemi M, Corelli RL, et al. A nontraditional faculty development initiative using a social media platform. Am J Pharm Educ. 2014;78(5):Article 105.

8. Davis G, Foley BJ, Horn E, Neal E, Redman R, Van Riper M. Creating a comprehensive faculty development program. J Faculty Develop. 2003;19(1):19-28.
9. Guglielmo BJ, Edwards DJ, Franks AS, et al. A critical appraisal of and recommendations for faculty development. Am J Pharm Educ. 2011;75(6):Article 122.

10. Haines ST, Persky AM. Faculty development: who, what, why, where, when, and how? Am J Pharm Educ. 2014;78(5):Article 97.

11. Lancaster JW, Stein SM, MacLean LG, Van Amburgh J, Persky AM. Faculty development program models to advance teaching and learning within health science programs. Am J Pharm Educ. 2014;78(5): Article 99.

12. Pintrich PR. The role of motivation in promoting and sustaining self-regulated learning. Int J Educ Res. 1999;31(6):459-470.

13. Appova A, Arbaugh F. Teachers' motivation to learn: implications for supporting professional growth. Prof Dev Educ. 2018;44(1):5-21.

14. Cross KP. Not can, but will college teaching be improved? New Dir Higher Educ. 1977;1977(17):1-15.

15. Salisbury A. The Theory of Teaching and Elementary Psychology. Chicago, IL: Row, Peterson \& Company; 1907.

16. Persky AM. Cost-benefit of instructional strategies. Am J Pharm Educ. 2014;78(8):Article 145.

17. Edwards RA, Kirwin J, Gonyeau M, Matthews SJ, Lancaster J, DiVall M. A reflective teaching challenge to motivate educational innovation. Am J Pharm Educ. 2014;78(5):Article 103.

18. Richlin L. Scholarly teaching and the scholarship of teaching. New Dir Teach Learn. 2001;2001(86):57-68.

19. Allen MN, Field PA. Scholarly teaching and scholarship of teaching: noting the difference. Int J Nurs Educ Scholarsh. 2005;2:Article 12. 